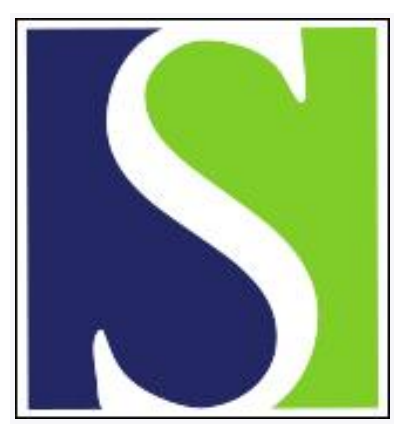

Scand J Work Environ Health 1979;5(3):178-187

https://doi.org/10.5271/sjweh.3091

Issue date: Sep 1979

Long-term sampling of airborne cadmium dust in an alkaline battery factory

by Adamsson $\mathrm{E}$

Affiliation: Department of Environmental Hygiene, The Karolinska Institute, S-10401 Stockholm 60, Sweden.

Refers to the following text of the Journal: 1976;2 suppl 1:19-31

Key terms: airborne cadmium dust; alkaline battery factory; battery factory; cadmium dust; long-term sampling; sampling strategy; workroom air sampling

This article in PubMed: www.ncbi.nlm.nih.gov/pubmed/20120565 


\title{
Long-term sampling of airborne cadmium dust in an alkaline battery factory
}

by EJDA ADAMSSON, M.D., M.Sc. ${ }^{1}$

\begin{abstract}
ADAMSSON, E. Long-term sampling of airborne cadmium dust in an alkaline battery factory. Scand. $j$. work environ. \& health 5 (1979) 178-187. Concentrations of cadmium in workroom air in a Swedish battery factory were estimated for the time period 1946 to 1976 . A sampling strategy was chosen before 389 stationary and 190 mobile measurements took place between December 1974 and February 1976. The studies showed that observations made by the company can be used together with data collected in the present study, the dust in the factory consists mainly of respirable particles, cyclic variation over time is absent, and type of work affects the concentration of airborne cadmium dust. Based on these findings earlier measurements in the factory were critically evaluated. It was found that, due to actions taken by the company, the average level of cadmium in workroom air decreased from about $5,000 \mu \mathrm{g} \mathrm{Cd} / \mathrm{m}^{3}$ air in 1946 to about $10 \mu \mathrm{g} \mathrm{Cd} / \mathrm{m}^{3}$ air in 1976 .
\end{abstract}

Key words: battery factory, cadmium dust, sampling strategy, workroom air sampling.

The effects of industrial exposure to cadmium (Cd) are well documented. Since Friberg (9), in 1950, presented data from extensive investigations showing that longterm exposure to cadmium oxide dust could cause both pulmonary and renal disease, a large number of studies in different countries have confirmed his findings. [For details consult Friberg (10) and Nordberg (31).]

There is still a lack of reliable data on cadmium exposure. This sort of data is

1 Department of Environmental Hygiene, The Karolinska Institute, and Department of Environmental Hygiene, National Environment Protection Board, Stockholm, Sweden.

Reprint requests to: Dr. Ejda Adamsson, Department of Environmental Hygiene, The Karolinska Institute, S-104 01 Stockholm 60, Sweden. essential for the estimation of the doseresponse relationship. In most studies only a few measurements have been made of concentrations of airborne cadmium dust, and those data have then often been used as estimates of exposure over decades (1, $3,9,14,18,22,23,33,34,39,41,42,43$ ).

The present study was undertaken to provide firmer ground for the estimation of exposure to cadmium and to evaluate past exposure in a factory manufacturing alkaline batteries.

Cadmium was studied in this report, but the results may be generally applicable to other types of industrial processes where continuous exposure to airborne dust occurs. Since there was simultaneous exposure to nickel, a similar study was performed on nickel concentrations in the air, and the results will be reported separately. 


\section{MATERIAL AND METHODS}

Suspended dust in air was collected on membrane filters. Large-volume sampling pumps (Reciprotor $506 \mathrm{R}$ ) with flow meters (Nordgas U $21 / 2$ ) were used at stationary sites, and portable low-volume sampling pumps (Casella) were used for personal sampling. With stationary equipment the sampling time varied from 3 to $8 \mathrm{~h}$. The aspiration rate of the pumps was around $15 \mathrm{l} / \mathrm{min}$. The dust particles were collected on 47-mm diameter filters. The personal samplers had an aspiration rate of about $2 \mathrm{l} / \mathrm{min}$, and the sampling time was 3 to $4 \mathrm{~h}$. The particles were collected on $37-\mathrm{mm}$ diameter filters. The filters (Gelman GA-6) had pores $0.45 \mu \mathrm{m}$ in diameter. Due to electrostatic forces even particles smaller than the pores of the filter were collected. The efficiency was high, greater than $99 \%$ for particles of all sizes and masses (12, 29). The filters were dissolved in concentrated nitric acid and chloric acid. Standards, together with unused filters, were treated in the same way.

The concentration of cadmium in the solution was analyzed with atomic absorption spectrophotometry (Perkin-Elmer 303, air-acetylene flame). The detection limit of the final solution $(10 \mathrm{ml})$ was about 0.01 $\mu \mathrm{g}$ of $\mathrm{Cd} / \mathrm{ml}$, which corresponds to detection limits of about $0.4 \mu \mathrm{g} \mathrm{Cd} / \mathrm{m}^{3}$ air for personal sampling and about $0.03 \mu \mathrm{g} \mathrm{Cd} /$ $\mathrm{m}^{3}$ air for stationary measurements.

In one of the studies personal samplers combined with cyclones (Casella) were used. The Casella cyclone is recommended by the National Swedish Board of Occupational Safety and Health. The cyclones give, at the recommended flow, no penetration at $7.0 \mu \mathrm{m}, 50 \%$ penetration at 5.0 $\mu \mathrm{m}$, and $75 \%$ penetration at $3.5 \mu \mathrm{m}$ for spheres of unit density, i.e., they provide a performance in agreement with that specified by the British Medical Research Council's Industrial Pulmonary Disease Committee and by the Johannesburg International Conference on Pneumoconiosis. For particles of greater density such as cadmium oxide hydrate $(\varrho=8.15)$ the aerodynamic equivalent sizes to $7.0,5.0$ and $3.5 \mu \mathrm{m}$ would be about 2.4, 1.7 and $1.2 \mu \mathrm{m}$, respectively $(13,27,28)$.

The sampling program was performed between December 1974 and February
1976. A total of 389 stationary measurements were made at 7 of the 15 sites used by the company in previous measurements. Mobile sampling was conducted within concentrated periods during December 1974, June 1975, September 1975, and January 1976. So that possible errors due to concentrated sampling could be corrected, 21 observations of the total 190 were spread out during the period October to December 1975. Sixty-five workers, 58 men and 7 women, all volunteers, carried a personal sampler at least one shift. Practical considerations made it reasonable to divide the workers into two groups, one heavily exposed and the other less exposed. The heavily exposed group was made up of cadmium briquette makers, cadmium rollers, spot welders, plate assemblers, insulation workers, and banders. The less exposed group was composed of nickel briquette makers, nickel rollers, press assistants, and projection welders.

The studies were undertaken in the same factory Friberg described in 1950 (9). Alkaline batteries with cadmium-nickel electrodes have been produced there since the early 1920 s.

All measurements took place in the assembly hall, where 140 persons worked in three shifts. This hall had an area of around $1,000 \mathrm{~m}^{2}$, and the general ventilation was $54,000 \mathrm{~m}^{3} / \mathrm{h}$.

\section{Earlier measurements in the factory}

There are no quantitative data on work conditions before 1946, but the workers were said to be in a very dusty environment. Observations of dust concentrations were sporadically performed in the years 1946 to 1971 . In all, 272 results from this period are available (table 1). The conditions during the observations are incompletely documented but were said to be "normal."

From 1972 on more detailed documentation is available. In the years 1972 to 1975 stationary measurements were performed sporadically by the company. In all, 328 observations were made at 15 different stations. In connection with the biological monitoring of new employees (19), a project which was started in February 1973, 246 observations were carried out with 
Table 1. Measurements made in the factory from 1946 to 1971.

\begin{tabular}{|c|c|c|c|c|}
\hline Sampling period & Sampler & Sampling methoda & Sampling time & $\begin{array}{l}\text { Number of } \\
\text { observations }\end{array}$ \\
\hline 1946, Nov. 15 & NIPHb & Impinger/Conimeter & $15-60 \mathrm{~min}$ & 5 \\
\hline 1946, Nov. & Friberg (9) & Impinger/Conimeter & $15-60 \mathrm{~min}$ & 5 \\
\hline 1947, Nov. & Friberg (9) & Impinger/Conimeter & $45-60 \mathrm{~min}$ & 5 \\
\hline 1948, Nov. & Friberg (9) & Impinger/Conimeter & $15-30 \mathrm{mir}$ & 9 \\
\hline 1949 , Nov. $10-11$ & NIPHb & Impinger/Conimeter & $15-30 \mathrm{~min}$ & 2 \\
\hline 1959 & Not known & Midget Impinger & Not known & $20^{c}$ \\
\hline 1959 & Not known & Midget Impinger & Not known & $21 \mathrm{c}$ \\
\hline 1960 & NIPHb & Impinger & Not known & $24^{c}$ \\
\hline 1960 & NIPHb & Millipore Filter & Not known & $29 c$ \\
\hline 1967, April & Company & Millipore Filter & $1-3 \mathrm{~h}$ & 30 \\
\hline 1967, Oct. $5-10$ & Company & Millipore Filter & $1-3 \mathrm{~h}$ & 23 \\
\hline 1967, Oct. $23-27$ & Company & Millipore Filter & $1-3 \mathrm{~h}$ & 24 \\
\hline 1967, Nov. & Company & Millipore Filter & $1-3 h$ & 8 \\
\hline 1969, June-Aug. & Company & Millipore Filter & $1-3 h$ & 15 \\
\hline 1969, Nov.-Dec. & Company & Millipore Filter & $1-3 h$ & 23 \\
\hline 1970, Sept. & Company & Millipore Filter & $1-3 \mathrm{~h}$ & 16 \\
\hline 1971, June & Company & Millipore Filter & $\mathrm{l}-3 \mathrm{~h}$ & 12 \\
\hline
\end{tabular}

a For descriptions of methods see the reports by Drinker \& Hatch (8), Hatch (15), Linch et al. (25), and Lippmann (27).

b NIPH = National Institute of Public Health.

c Mean values of two to eight individual samples.

Table 2. Comparisons between the stationary and personal sampling results.

\begin{tabular}{llccccc}
\hline Station & \multicolumn{1}{c}{$\begin{array}{c}\text { Category of } \\
\text { workers }\end{array}$} & $\begin{array}{c}\text { Number of } \\
\text { pairs of } \\
\text { observa- } \\
\text { tions }\end{array}$ & $\begin{array}{c}\text { Correlation } \\
\text { coeffici- } \\
\text { ent }\end{array}$ & $\begin{array}{c}\text { Arithmetic mean } \\
\left(\mu \mathrm{g} \mathrm{Cd} / \mathrm{m}^{3} \text { air }\right)\end{array}$ & $\begin{array}{c}\text { Station- } \\
\text { ary }\end{array}$ & $\begin{array}{c}\text { Sersonal } \\
\text { Pry/ } \\
\text { personal } \\
\text { ratio }\end{array}$ \\
\hline B & Cadmium briquette & & & & & \\
M & makers & 40 & +0.55 & 13.6 & 35.4 & 0.38 \\
P & Plate assemblers & 36 & +0.39 & 17.8 & 20.5 & 0.87 \\
\hline
\end{tabular}

personal samplers. The sampling time for both the stationary and personal sampling was, on the average, $3 \mathrm{~h}$.

\section{Sampling strategy}

Since continuous sampling was economically and practically unfeasible, the choice of day, time, place, and mode of sampling had to be optimal for noncontinuous sampling. So that the ultimate goal of quantifying the long-term external exposure to airborne cadmium dust could be attained, the problem of estimating concentrations was divided into the following six operational questions.
1. Can the distribution of values obtained be described? Knowing the type of distribution is economical from the statistical point of view since a known distribution provides more information in proportion to the number of values than does an unknown distribution. Recent work has shown that occupational environmental data are best described by fitting a lognormal distribution to the measurements $(6,11,30,35,36)$.

The confidence limits on the arithmetic mean assuming log-normal distribution were computed from a formula given by Coenen (6). In all statistical evaluations the level of confidence was chosen to be $95 \%$. 
Series of data were analyzed for every station and every category of workers (17, 26).

2. Can values obtained from stationary measurements be used in estimating the dose? For the investigation of whether stationary sampling could be useful, results obtained from personal samplers were compared to those collected from stationary devices during the same shifts. Eighty-five pairs from three different categories of workers and their corresponding stations were analyzed.

3. Can data obtained by the company be used? For the evaluation of whether data from the company could be used together with data collected by the author, some randomly chosen workers carried two personal samplers at the same time. The samplers were randomly fixed to the shoulders. One filter of the pair was analyzed at the laboratory of the Department of Environmental Hygiene and the other filter was analyzed in the laboratory of the company. In all, 20 pairs of filters were examined.

4. Does particle size influence the results? So that information could be obtained on the extent to which nonrespirable particles, i.e., particles with an aerodynamic diameter greater than $5 \mu$, would affect the results, the same investigation technique as for question 3 was chosen. Some randomly chosen workers were equipped with two personal samplers, one combined with a cyclone. The experiment was carried out during eight work shifts, each person wearing his samplers one shift. Twenty-eight pairs of results were gathered after those personal samplers combined with cyclones which did not have a constant flow, i.e., the design flow $+/-10 \%$ (16), were disqualified.

5. Is there any variation over time? So that any variation occurring during the workday could be determined, data obtained by personal sampling before and after noon were compared.

For the determination of whether there were any differences in the conditions between different workdays, different days within the same week, or between different days within a longer time period, a series of stationary measurements was carried out. The concentrations of cadmium dust were measured at five different stations during 50 workdays. The sampling time was around $8 \mathrm{~h} / \mathrm{d}$. The data obtained were analyzed by use of an analysis of variance method (7).

6. Does type of job affect the dose? For the optimal allocation of resources it is of interest to know about the magnitude of different causes of variation. In order to obtain this information, an analysis of components of variance methods was used (40).

\section{RESULTS}

Due to the probable influence of the use of plastic-covered steel strips which began in June 1973 and then increased to the extent that all briquettes were plasticcovered in June 1975, data collected in December 1974 were treated apart from data collected between June 1975 and February 1976.

\section{Distribution of data}

All series of data proved to fit the requirements for $\log$ normality.

\section{Personal versus stationary sampling}

A comparison between personal and stationary sampling resulted in correlation coefficients varying between +0.32 and +0.55 (table 2). The correlation coefficients for cadmium briquette makers and plate assemblers were statistically significant. A Student's t-test on the pairs of series showed a significant difference only for the cadmium briquette makers.

\section{Company's versus author's data}

The arithmetic mean of the values obtained by the company was $14.4 \mu \mathrm{g} \mathrm{Cd} / \mathrm{m}^{3}$ 
air and that of my data achieved in parallel was $11.4 \mu \mathrm{g} \mathrm{Cd} / \mathrm{m}^{3}$ air. The correlation $(\mathrm{N}=20)$ was 0.16 , not statistically significant. Because of the inhomogeneity of the variances of the log-transformed series, no test of the equality of the means could be performed. However, the series of differences between the two components of each pair, ranging from -14.76 to $+12.21 \mu \mathrm{g} \mathrm{Cd} / \mathrm{m}^{3}$ air, was normally distributed and a Student's t-test revealed that the differences may have arisen by chance.

\section{Size of particles}

The arithmetic mean of observations made without a cyclone was $12.0 \mu \mathrm{g} \mathrm{Cd} / \mathrm{m}^{3}$ air, and the arithmetic mean of values obtained with personal samplers combined with cyclones was $10.0 \mu \mathrm{g} \mathrm{Cd} / \mathrm{m}^{3}$ air. The correlation $(\mathrm{N}=28)$ was 0.19 , not statistically significant. Both distributions fit the requirements for log normality. A Student's t-test on the log-transformed series showed no difference between the means. The range of differences between the two components of each pair was -67.2 to $+18.9 \mu \mathrm{g} \mathrm{Cd} / \mathrm{m}^{3}$ air. The series of differences was normally distributed, and a Student's t-test suggested that the differences may have arisen by chance.

\section{Variation over time}

During the period June 1975 to January 1976, 36 observations were made on cadmium briquette makers. Seventeen observations were made in the morning and 19 in the afternoon. The arithmetic mean was $11.2 \mu \mathrm{g} \mathrm{Cd} / \mathrm{m}^{3}$ air for samples taken before noon and $11.9 \mu \mathrm{g} \mathrm{Cd} / \mathrm{m}^{3}$ air for samples taken after noon. Both distributions fit the requirements for log normality. A Student's t-test showed no significant difference between the means.

The series for each of the workdays for five stations were examined, and they proved to fit the requirements for log normality. Hypotheses of the homogeneity of variances were accepted for all stations. No significant difference among the means of the workdays was found for any of the stations (table 3).
Table 3. Average ( $\mu \mathrm{g} \mathrm{Cd} / \mathrm{m}^{3}$ air) of 10 observations made from September to November 1975 (workday means).

\begin{tabular}{lccccc}
\hline & \multicolumn{5}{c}{ Station } \\
\cline { 2 - 6 } Day & $\mathrm{B}$ & $\mathrm{I}$ & $\mathrm{K}$ & $\mathrm{M}$ & $\mathrm{P}$ \\
\hline Monday & 17.7 & 7.5 & 14.3 & 11.3 & $\mathbf{9 . 0}$ \\
Tuesday & 21.2 & 6.6 & 14.8 & 10.8 & $\mathbf{8 . 3}$ \\
Wednesday & 16.7 & 6.1 & 13.8 & 11.8 & 8.7 \\
Thursday & $\mathbf{1 6 . 4}$ & 7.2 & 13.7 & 11.1 & $\mathbf{8 . 9}$ \\
Friday & $\mathbf{1 4 . 6}$ & $\mathbf{6 . 4}$ & 13.4 & 12.8 & 7.5 \\
\hline
\end{tabular}

The geometric means for each individual day were examined, and the series of days within the same week proved to fit the demand of homogeneity of variances for all weeks. Statistical tests showed no differences for days within the same week.

The series for the 50 individual days were compatible, and no statistical difference was obtained among the means.

\section{Effect of type of job}

A hypothesis of equality among the means for all ten categories of workers was rejected. However, when the workers were divided into categories of heavily exposed and less exposed, the hypotheses of equal means within each subgroup were accepted. The arithmetic mean of 139 observations collected between June 1975 and January 1976 from heavily exposed workers was $11.8 \mu \mathrm{g} \mathrm{Cd} / \mathrm{m}^{3}$ air with confidence limits of the arithmetic mean of 10.9 and $14.6 \mu \mathrm{g} \mathrm{Cd} / \mathrm{m}^{3}$ air (fig. 1). The arithmetic mean of 32 observations collected during the same time on less exposed workers was $7.3 \mu \mathrm{g} \mathrm{Cd} / \mathrm{m}^{3}$ air with confidence limits of 6.2 and $12.0 \mu \mathrm{g} \mathrm{Cd} / \mathrm{m}^{3}$ air.

\section{Estimations of concentrations between 1946 and 1976}

Kjellström (19), who had access to almost all the results from 1946 to 1974 used in this study, estimated the "true" (quotation marks are Kjellström's) average cadmium concentration in the assembly plant 